\title{
Proceeding
}

8th INSHS International Christmas Sport Scientific Conference, 5-7 December 2013. International Network of Sport and Health

Science. Szombathely, Hungary

\section{The dynamics of changes in the indicators of running economy within 48 hours after application of explosive strength training}

\author{
TOMÁŠ KALINA , JAN CACEC, PAVEL GRASGRUBER \\ Faculty of Sports Studies, Masaryk University, Brno, Czech Republic
}

\begin{abstract}
Kalina, T., Cacec, J. \& Grasgruber, P. The dynamics of changes in the indicators of running economy within 48 hours after application of explosive strength training. J. Hum. Sport Exerc., 9(Proc 1), ppS417S421. The aim of this study was to determine the dynamics of the indicators of running economy (VO2-BM$1 \cdot \min -1$ and $\triangle \mathrm{VO} 2 \cdot \mathrm{BM}-1 \cdot \mathrm{min}-1)$ within 48 hours after the application of explosive strength intervention (ESI). Nine university students, recreational athletes (age $23.8 \pm 1.56$ years, height $178 \pm 4.8 \mathrm{~cm}$, weight $74.8 \pm 2.91 \mathrm{~kg}$ ) underwent ESI (6 explosive strength exercises, 3 sets, 8 reps, rest $90 \mathrm{sec}$, maximum intensity) aimed mainly at lower limbs. The testing of running economy (RE) was performed during four separate measurements $(-48,0,24$ and $48 \mathrm{~h} ; 0=$ test immediately after the intervention) at 8, 10, $12 \mathrm{~km} \cdot \mathrm{h}$ 1 (5 min intervals; the last $60 \mathrm{sec}$ of each level were recorded). It was found that when compared with the pretest values $(-48 \mathrm{~h})$, the average $\Delta \mathrm{VO} 2 \cdot \mathrm{BM}-1 \cdot \mathrm{min}-1$ at $8 \mathrm{~km} \cdot \mathrm{h}-1$ changed by $+3.8 \%$ immediately after the intervention (0), by $+1.6 \%$ after $24 \mathrm{~h}$, and by $0 \%$ after $48 \mathrm{~h}$. At $10 \mathrm{~km} \bullet \mathrm{h}-1$, the changes were $6.3-4.3-$ $0.4 \%$, and at $12 \mathrm{~km} . \mathrm{h}-1$ they were $5.2-4.3-1.5 \%$. According to the available literature, it was realistic to expect a peak of $\mathrm{O} 2$ consumption during $48 \mathrm{~h}$ after the intervention, but this was not observed. The results show the greatest deterioration of RE immediately after the intervention, with a subsequent decline of 02 consumption to resting levels within $48 \mathrm{~h}$. Key words: PLYOMETRIC TRAINING, COST OF RUNNING, ACUTE EFFECT.
\end{abstract}

Corresponding author. Faculty of Sports Studies, Masaryk University, Brno, Czech Republic.

E-mail: tkalina@fsps.muni.cz

8th INSHS International Christmas Sport Scientific Conference, 5-7 December 2013. International Network of Sport and Health Science. Szombathely, Hungary.

JOURNAL OF HUMAN SPORT \& EXERCISE ISSN 1988-5202

(c) Faculty of Education. University of Alicante

doi:10.14198/jhse.2014.9.Proc1.27 


\section{INTRODUCTION}

Running economy (RE), together with the value of the anaerobic threshold and maximal oxygen uptake (VO2 max), is regarded as one of key factors determining aerobic performances (Basset and Howley, 2000).

The available research of RE has already resolved most problems related to the impact of various intervention programs on the indicators of RE. The effect of long-term (several weeks') programs on changes in RE suggests that plyometric interventions can positively affect RE. For example, the study of Saunders et al. (2006) conducted during 9 weeks in highly trained runners showed a positive influence of a plyometric intervention on running economy. An interesting fact is that these positive changes were observed only at the highest tested speed $(14,16$ and $18 \mathrm{~km} . \mathrm{h}-1)$. Similar results in elite runners were reported by Turner et al. (2003), who demonstrated a positive impact of plyometric methods on changes of $\mathrm{RE}$, although they did not confirm the expected mechanism of these changes (storage and utilization of the elastic energy). Conversely, Grieco et al. (2012) showed that a plyometric program lasting for 10 weeks had no influence on the indicators of RE (at the speed of $9 \mathrm{~km} . \mathrm{h}-1$ ) in a women's soccer team.

To our knowledge, an acute effect of plyometric training on RE has not been described in literature. There are indications pointing to an increased level of fatigue and muscle tenderness after plyometric exercises, because the culmination of muscular sensitivity occurs after about 48 hours (Kampmiller \& Vanderka, 2006). It can be assumed that the consumption of $O 2$ (as an indicator of RE) during constant speed running, at a fatigue caused by a previous plyometric training, is higher than the consumption of $\mathrm{O} 2$ at the same speed in fully recovered individuals.

\section{MATERIAL AND METHODS}

\section{Participants}

The research was conducted in nine randomly selected recreational athletes (males), students of the Masaryk University. Their mean age was $23.8 \pm 1.56$ (mean \pm SD) years, their mean measured height was $178 \pm 4.8 \mathrm{~cm}$ and weight $74.8 \pm 2.91$. All students participated in the study voluntarily.

\section{Procedures}

The acute effect of a plyometric intervention on indicators of RE was examined through four separate tests of running economy at different time intervals since the plyometric intervention. First, a baseline measurement (-1), which was to serve for the comparison of changes in RE (caused by the subsequent interventions), took place 48 hours before the plyometric exercise. It was followed by a measurement at the time $0(0)$, ie. immediately after the plyometric exercises, and then by measurements after 24 hours (1) and 48 hours (2). We focused on changes in the average $\triangle \mathrm{VO} 2 \cdot \mathrm{BM}-1 \cdot \mathrm{min}-1$ (the ratio between acute oxygen uptake and baseline oxygen uptake, ie. "-1", expressed in millilitres of oxygen per minute and kilograms of body mass) at running speeds of 8,10 and $12 \mathrm{~km} \cdot \mathrm{h}-1$ on the treadmill with a $1 \%$ slope. Running speeds were selected in order to test athletes at speeds below the anaerobic threshold. The interval at each speed lasted five minutes.

After the completion of a standard warm-up (which included five minutes of dynamic stretching followed by a 5-minute running load on each speed described above), the speed intervals followed one after another, without rest. VO2 recording took place during the last 2 minutes of the load using the device Metalyzer $3 \mathrm{~b}$ 
(Cortex, Biophysik $\mathrm{GmbH}$, Germany), the breath-by-breath analysis. The testing of RE was performed on the treadmill (Catana, Lode, The Netherlands).

The plyometric training included six explosive strength exercises that were performed in 3 sets of 8 repetitions. The interval of rest between sets and exercises was set to a common standard. The exercises were as follows:

1) Jump squats with a barbell $(30 \mathrm{~kg})$

2) Vertical jumps off the bench $(20 \mathrm{~cm})$

3) Hand jump push-ups

4) Front lunges with a barbell $(20 \mathrm{~kg})$

5) "Skater" (20 kg plate on the chest)

6) Horizontal jumps off the bench $(20-40 \mathrm{~cm})$

The testing was conducted at a constant temperature of $20 \pm 1{ }^{\circ} \mathrm{C}$, always in the same shoes and the same clothes. Two days before the initial examination and during the execution of the research, the tested subjects were asked to refrain from any sports activities. Before each measurement, the calibration of Metalyzer $3 b$ was performed by a calibration syringe ( 3 Liter Calibration Syringe, Cortex, Germany).

\section{Analysis}

The obtained data were expressed as $\triangle \mathrm{VO} 2 \cdot \mathrm{BM}-1 \cdot \mathrm{min}-1$. A data analysis was performed using pre-test to post-tests $(0 \mathrm{~h}, 24 \mathrm{~h}, 48 \mathrm{~h})$ changes that were assessed by analysis of variance with repeated measures. The level of $p<0.05$ was considered as statistically significant. The software program Statistica 12 (StatSoft, Tulsa, USA) was used for all statistical analyses. Considering that we compared results of two independent studies with the same design, but with a different type of training, we used a relative expression of changes in RE (\%).

\section{RESULTS}

We found that when compared with the pre-test values $(-48 \mathrm{~h})$, the average $\Delta \mathrm{VO} \cdot \mathrm{BM}-1 \cdot \mathrm{min}-1$ at $8 \mathrm{~km} \bullet \mathrm{h}-1$ changed by $+3.8 \%$ immediately after the intervention ( 0 ), by $+1.6 \%$ after $24 \mathrm{~h}$, and by $0 \%$ after $48 \mathrm{~h}$. At 10 $\mathrm{km} \cdot \mathrm{h}-1$, the changes were $6.3-4.3-0.4 \%$, and at $12 \mathrm{~km} . \mathrm{h}-1$ they were $5.2-4.3-1.5 \%$. Plyometric training did not induce significant changes $(p<0.05)$ in RE neither during the monitored intervals $(0,1,2)$, nor at the tested speeds (Table $1 \&$ Figure 1). The most striking changes in running economy (when compared to the interval -1) were observed during the interval 0 (at all three speeds) and at $10 \mathrm{~km} \cdot \mathrm{h}-1$. During the intervals 1 and 2 , the average $\triangle \mathrm{V} 02 \cdot \mathrm{BM}-1 \cdot \min -1$ tended to decrease at all speeds, particularly during the interval 2, the pointer value RE moved to the edge of the measurement input (-1).

Table 1. Descriptive Statistics of running economy (deltaVO2)

\begin{tabular}{ccccccc}
\hline $\begin{array}{c}\text { Time } \\
\text { (day) }\end{array}$ & $\begin{array}{c}\text { Speed } \\
(\mathbf{k m} \cdot \mathbf{h}-\mathbf{1})\end{array}$ & $\begin{array}{c}\text { deltaVO2 } \\
\text { (Mean) }\end{array}$ & $\begin{array}{c}\text { deltaV02 } \\
\text { (Std.Dev.) }\end{array}$ & $\begin{array}{c}\text { deltaV02 } \\
\text { (Std.Err) }\end{array}$ & $\begin{array}{c}\text { deltaVO2 (- } \\
\mathbf{9 5 , 0 0 \% )}\end{array}$ & $\begin{array}{c}\text { deltaVO2 } \\
(+95,00 \%)\end{array}$ \\
\hline 0 & 8 & 1.038 & 0.049 & 0.016 & 1.001 & 1.076 \\
0 & 10 & 1.063 & 0.029 & 0.010 & 1.041 & 1.086 \\
0 & 12 & 1.052 & 0.032 & 0.011 & 1.027 & 1.076 \\
1 & 8 & 1.016 & 0.073 & 0.024 & 0.960 & 1.072 \\
1 & 10 & 1.043 & 0.052 & 0.017 & 1.003 & 1.084 \\
\hline
\end{tabular}




\begin{tabular}{ccccccc}
1 & 12 & 1.043 & 0.043 & 0.014 & 1.010 & 1.076 \\
2 & 8 & 0.993 & 0.101 & 0.034 & 0.916 & 1.071 \\
2 & 10 & 1.004 & 0.081 & 0.027 & 0.942 & 1.066 \\
2 & 12 & 1.015 & 0.047 & 0.016 & 0.979 & 1.052 \\
\hline
\end{tabular}

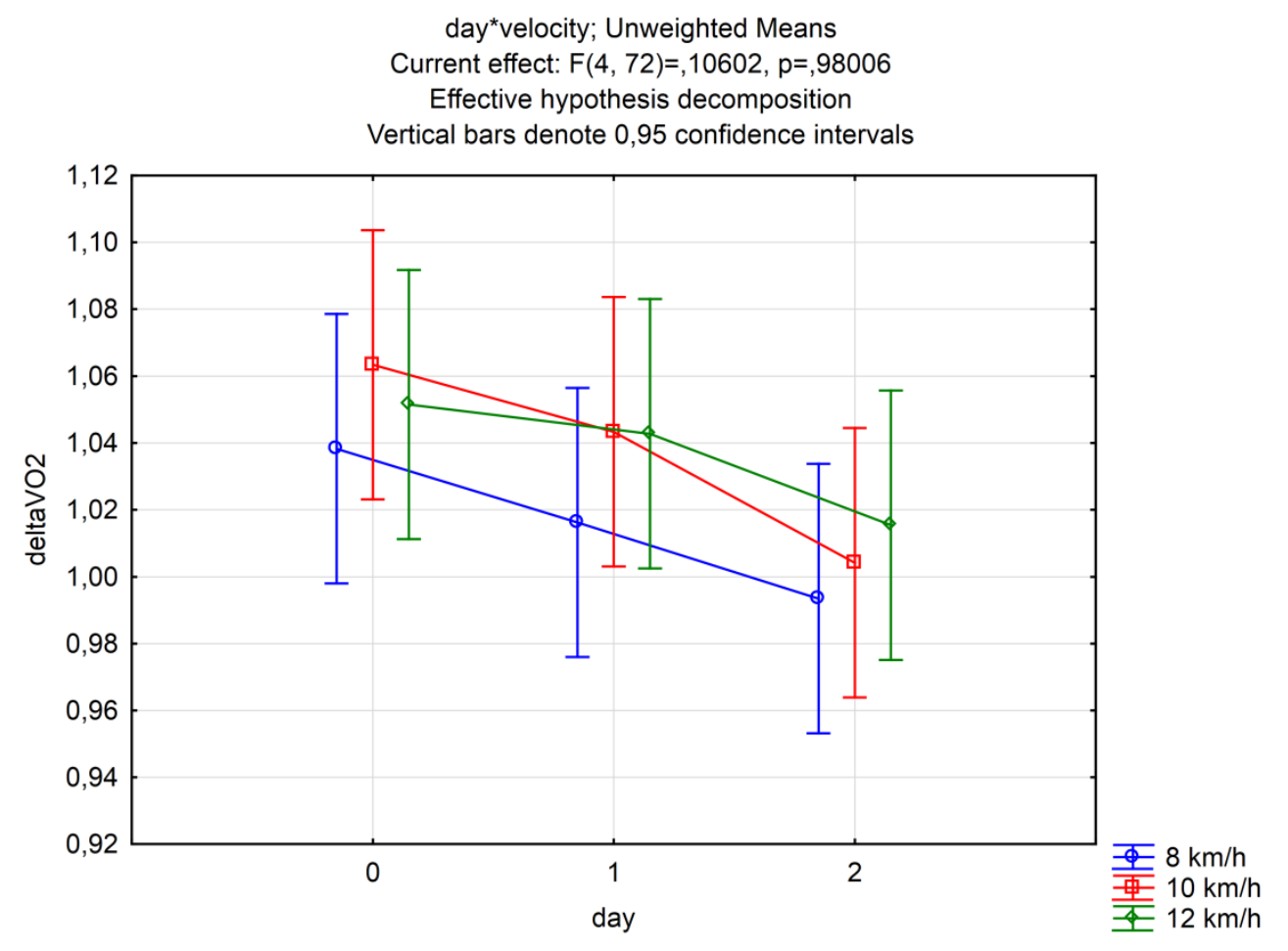

Figure 1. Changes in running economy $(\triangle V O 2 \cdot B M-1 \cdot \min -1)$ in ratio to base-line measurement

\section{DISCUSSION}

The documented changes of RE induced by plyometric training were not statistically significant. Nevertheless, it is interesting that in some cases, the changes reached values around $6 \%$, when compared to the pre-test (baseline). We can assume that the intervention was performed with a sufficiently strong stimulus to cause a significant deterioration in RE immediately after the intervention. In fact, the tested subjects (without exception) reported that the subjective assessment of fatigue was high, especially during the interval 1 (24 hours after the intervention).

The time interval that matched the measured largest deterioration $\mathrm{RE}(0)$ does not premise the rate increased muscle sensitivity after 48 hours as indicated Kampmiller and Vanderka (2006). This may be due to the insufficient strength of the plyometric stimulus, which did not produce the expected changes at the cellular level, respectively. From our perspective, it would be appropriate to extend the investigation further and monitor other indicators (eg. creatine kinase), which may demonstrate a relationship between the degree of fatigue after a plyometric intervention and changes in RE. 


\section{CONCLUSIONS}

Plyometric training did not elicit the expected changes in the dynamics of RE during the intervals 0,24 and 48 hours after the plyometric intervention. The results so broadly follows that when we set design does not occur in the time interval $0-48 \mathrm{~h}$ after the intervention to the accumulation of fatigue that would materially affect the monitored parameters. The usability of this fact is seen in the planning of endurance load below the level of anaerobic threshold, where we can calculate the signal level values of RE.

\section{SOURCE OF FUNDING FOR THE STUDY}

This investigation was conducted within the framework of a specific students' research at the Masaryk University 0790/2012 "Factors affecting the economy of running (the effect of explosive strength training and stretching acutely applied before performance on the economy of running) II".

\section{REFERENCES}

1. Bassett, D.R. \& Howley, E.T. (2000) Limiting factors for maximum oxygen uptake and determinants of endurance performance. Med Sci Sport Exer, 32, pp.70-84.

2. Greico, C.R., Cortes, N., Greska, E.K., Lucci, S. \& Onate, J.A. (2012). Effects of a combined resistance-plyometric training program on muscular strength, running economy, and VO2 peak in division i female soccer players. J Strength Cond Res, 26(9), pp.2570-2576.

3. Kampmiller, T. \& Vanderka, M. (2006) Oneskorená svalová citlivost „svalová horúčka“ v kondičnej príprave športovcov. Atletika, pp.84-88.

4. Saunders, P.U., Telford, R.D., Pyne, D.B., Peltola, E.M., Cunningham, R.B., Gore, C.J. \& Hawley, J.A. (2006). Short-term plyometric training improves running economy in highly trained middle and long distance runners. Med Sci Sport Exer, 20(4), pp.947-954.

5. Turner, M.A., Owings M. \& Schwane A.J. (2003). Improvement in running economy after 6 weeks of plyometric training. J Strength Cond Res, 17(1), pp.60-67. 